\title{
Aplicação da Teoria dos Conjuntos Vagos na Medida e Gestão do Risco Cambial Económico
}

\author{
Lúcia Maria Portela de Lima Rodrigues
}

\section{ResUMO}

Neste artigo apresentamos um modelo de inferência em lógica vaga para a medida da exposição das empresas ao risco de câmbio económico. No sentido de ultrapassar as insuficiências da contabilidade de gestão tradicional na captação do fenómeno do risco cambial, este modelo avalia, de uma forma aproximada, o efeito das variações nas taxas de câmbio reais nos lucros operacionais e na posição competitiva da empresa. Relativamente ao efeito nos lucros operacionais, podemos dizer que depende do efeito das variações nas taxas de câmbio reais nos proveitos e nos custos operacionais, sendo ambos analisados como uma dupla variação, a dos preços e a das quantidades. No que respeita ao efeito das variações das taxas de câmbio reais na posição competitiva, consideraremos que depende essencialmente das variações observadas nos custos relativos dos concorrentes e nas suas quotas de mercado. Para testarmos o modelo utilizamos a unidade estratégica de negócios Fios de uma grande empresa têxtil portuguesa.

Palavras-chaves: modelo em lógica vaga; risco cambial económico; contabilidade de gestão estratégica; estudo de caso em Portugal.

\begin{abstract}
In this study we present a model derived using fuzzy sets theory to measure the firm's exposition to economic exchange risk. In order to overcome the shortcomings of accounting in capturing the exchange risk phenomenon, this model evaluates approximately the effects of variations in real exchange rates on operational income and the competitive position of the firm. In this model operational income depends on the effects of variations in real exchange rates on operational benefits and costs. Operational benefits and costs are both analyzed as a double variation in prices and quantities. In what concerns the effect of variations in real exchange rates on the competitive position of the firm, we consider that it depends mainly on observed variations in the relative costs of competitors and their market shares. In order to test empirically the model we study the case of a strategic business unit of yarns in a large textile enterprise.
\end{abstract}

Key words: fuzzy logic model; economic foreign exchange risk; strategic management accounting; case study in Portugal. 


\section{INTRODUÇĀO}

Tradicionalmente, os sistemas contabilísticos têm sido dirigidos para as transaç̧ões financeiras e não têm tratado o problema do risco de câmbio económico, apesar de este tipo de risco poder ser muito maior do que o risco de câmbio financeiro (risco de câmbio de transacção e risco de câmbio de tradução). $\mathrm{Na}$ verdade, as variações nas taxas de câmbio reais provocam efeitos de concorrência que podem pôr em causa a sobrevivência da empresa e, por isso, não podem ser ignorados pela contabilidade de gestão estratégica.

O efeito de concorrência global provocado pelas variações nas taxas de câmbio reais é composto por um grande número de pequenos efeitos de concorrência, incluindo não só os resultantes dos custos e proveitos operacionais em moeda estrangeira, mas também os resultantes dos custos e proveitos operacionais domésticos que estão sujeitos à concorrência internacional, bem como os efeitos na posição competitiva a médio e longo prazo da empresa em relação aos concorrentes. Dada a complexidade deste efeito de concorrência e dadas também as interacções complexas das flutuações cambiais e outros factores que afectam a procura e a competitividade, os modelos exactos e, portanto, as medidas exactas deste tipo de risco serão talvez impossíveis. Contudo, porque a definição de uma estratégia cambial exige que se tenha uma ideia aproximada da exposição económica da empresa ou da unidade estratégica de negócios e porque, muitas vezes, para gerir não é necessário fazer avaliações exactas dos problemas, mas apenas avaliações aproximadamente correctas, enveredamos por um modelo de inferência (if...then...) em lógica vaga. Consideramos que este tipo de modelo é o método mais útil e apropriado para o desenvolvimento de um expert system para julgamentos sobre o risco cambial económico, dada a incerteza relacionada com o seu processo de avaliação.

O objectivo deste artigo é apresentar um modelo em lógica vaga de avaliação do risco de câmbio económico. Assim, na segunda seção faremos uma breve introdução à teoria dos conjuntos vagos com vista a clarificar um pouco a matemática utilizada na construção do modelo apresentado na seção seguinte. Na quarta seção apresentamos os resultados obtidos com a aplicação empírica e por fim traçaremos as principais conclusões. 


\section{Teoria dos Conjuntos Vagos/ Contabilidade de Gestão Estratégica}

A teoria dos conjuntos vagos (fuzzy set theory) surgiu com Zadeth (1965) e constitui uma generalização da teoria dos conjuntos ordinários. De facto, a teoria dos conjuntos ordinários trata a relação de pertença de uma forma binária: um elemento ou pertence ou não pertence a um conjunto. Pelo contrário, a teoria dos conjuntos vagos permite relações de pertença graduais, substituindo a lógica de verdadeiro ou falso, branco ou preto, por uma lógica onde são permitidos diferentes matizes e graus de pertença. A função característica de pertença nos conjuntos ordinários é enquadrada no conjunto de dois elementos $\{0,1\}$, o que requer demasiada precisão, que não existe, por exemplo, na análise do risco. Por outro lado, nos conjuntos vagos, a função característica de pertença $(\mu(\mathrm{x}))$ adquire qualquer valor do segmento [0,1], o que permite tratar situações de elementos que não estão completamente dentro de um conjunto, mas também não estão completamente fora dele. Ou seja, a teoria dos conjuntos vagos permite um grau de pertença gradual e é, por isso, mais representativa do mundo real, onde as verdades parciais são mais comuns que as verdades absolutas.

A lógica vaga pode ser vista como uma linguagem matemática, no âmbito da teoria dos conjuntos vagos, que nos permite traduzir afirmações complicadas em linguagem natural para o formalismo matemático. Devido à sua capacidade para incorporar variáveis vagas que podem ser identificadas por um conjunto de características qualitativas, a lógica vaga permite a introdução de realismo no processo de avaliação dos efeitos da flutuação cambial nos lucros operacionais e na posição competitiva da empresa ou da unidade estratégica de negócio.

Por sabermos que:

- não é possível levar a cabo uma avaliação exacta ${ }^{(1)}$ do risco de câmbio operacional, mas que é importante ter uma ideia aproximadamente correcta dos efeitos da concorrência provocados pelas taxas de câmbio numa empresa ou unidade estratégica de negócios;

- que a teoria dos conjuntos vagos permite levar a cabo avaliações do risco em situações vagas, imprecisas e onde domina o subjectivismo;

- este conjunto de circunstâncias levou-nos a construir o modelo que apresentaremos na seção seguinte. Ao avaliarmos o risco de câmbio operacional em termos de uma aproximação linguística usando conjuntos vagos, tentaremos obter uma resposta aproximada para um problema complexo, perante as alternativas de uma resposta exacta mas provavelmente mais incorrecta, ou nenhuma resposta. 
A falta de interesse demonstrada até agora pelos académicos e profissionais da contabilidade no estudo do risco de câmbio económico justifica-se em grande medida pelo pequeno interesse que se tem observado, até agora, no desenvolvimento e implementação de sistemas contabilísticos estratégicos. A contabilidade de gestão estratégica surgiu recentemente (Simmonds [1981] fala pela primeira vez deste novo paradigma contabilístico), como uma forma de se fazer face à limitações da contabilidade de gestão tradicional. Contudo, apesar da grande competitividade que se verificou durante a década de 90 , verifica-se um grande atraso no desenvolvimento e implementação de sistemas contabilísticos estratégicos. Para incrementar este desenvolvimento, como Rangone (1997) acreditamos que é possível fazer uma integração entre contabilidade de gestão e estratégia utilizando enquadramentos linguísticos vagos.

\section{Modelo de Inferéncia em lógica Vaga para a Avaliação do Risco de CÁmbio ECONÓMICO}

A definição de uma política de cobertura cambial exige que se tenha pelo menos uma ideia aproximada da exposição económica. Como Pitt-Watson (1990, p. 137), pensamos que:

“a exposição económica pode ser medida e, além disso, pode ser coberta. Contudo a medida requer não apenas conhecimentos de gestão financeira, mas também uma compreensão da estratégia do negócio. Só quando todas as exposições são compreendidas é que a empresa pode decidir se deverá cobri-las, ou simplesmente publicar a sua existência para que os accionistas tenham conhecimento delas. [...] Isto não é uma busca trivial. A exposição económica não pode ser definida com a mesma precisão que a exposição financeira".

\section{As Componentes do Modelo}

A Figura 1 traduz que o nível de risco cambial económico depende essencialmente do efeito que as variações nas taxas de câmbio reais têm sobre os lucros operacionais e sobre a posição competitiva da empresa. Relativamente ao efeito nos lucros operacionais, podemos dizer que depende do efeito das variações nas taxas de câmbio reais nos proveitos e nos custos operacionais, sendo ambos analisados como uma dupla variação, a dos preços e a das quantidades. No que respeita ao efeito das variações das taxas de câmbio reais na posição competitiva, 
consideraremos que depende essencialmente das variações observadas nos custos relativos dos concorrentes e nas suas quotas de mercado.

\section{Figura 1: As Componentes do Modelo de Inferência Vago para Avaliação} do Risco de Câmbio Económico

\section{NÍVEL DE RISCO DE CÂMBIO ECONÓMICO}

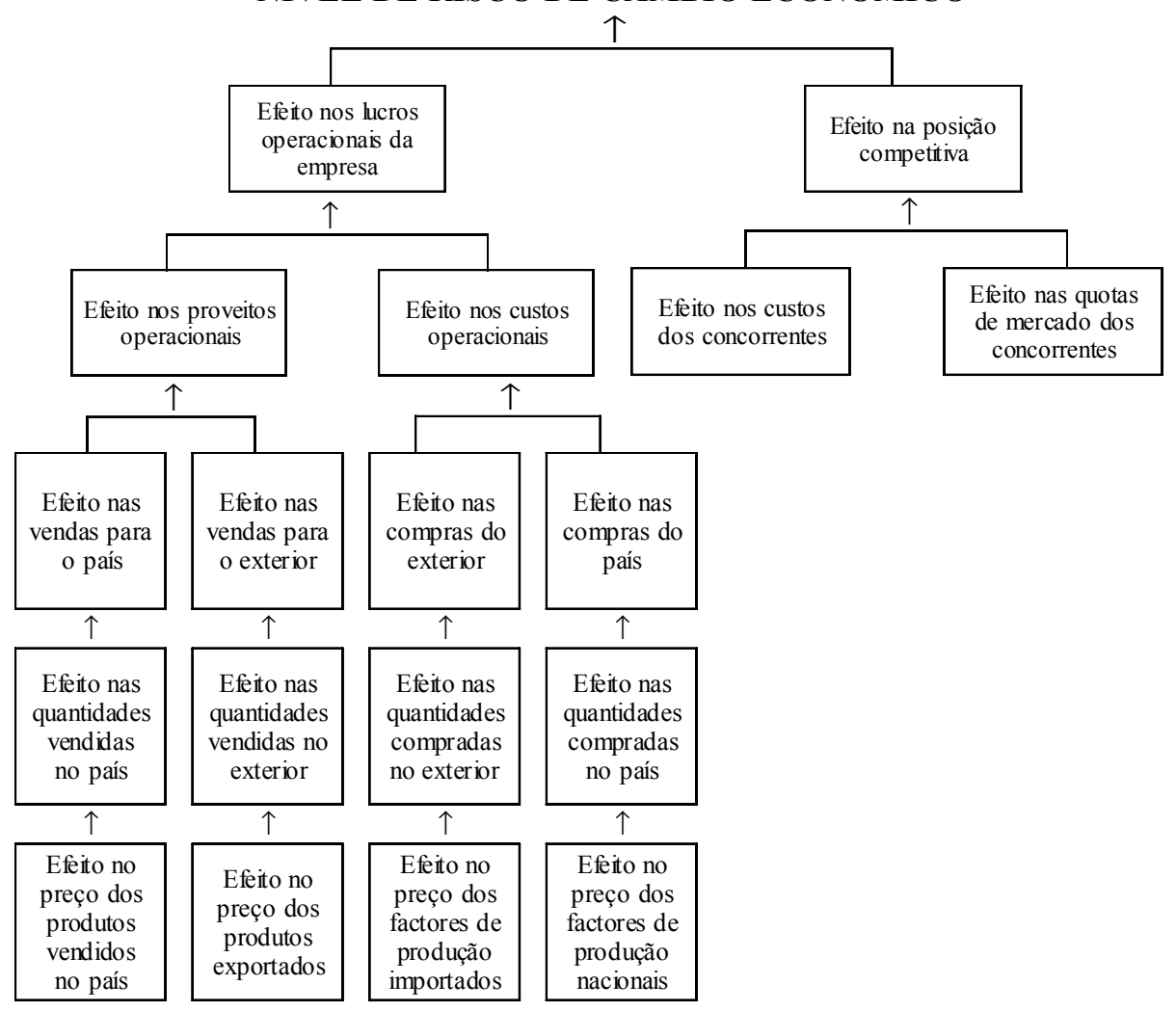

\section{Esquema das Componentes}

O primeiro passo no desenvolvimento de cada componente do sistema vago obriga à representação gráfica dessa componente. Sistematizam-se as variáveis input e output específicas de cada componente, bem como, as relações entre estas variáveis. A Figura 2 ilustra, como exemplo, a componente que determina o efeito da flutuação do escudo no preço dos produtos vendidos para o mercado interno, podendo observar-se que são identificadas cinco variáveis input primárias: elasticidade da oferta, elasticidade da procura, elasticidade cruzada da procura dos produtos, número de empresas estrangeiras em relação às domésticas e grau de concorrência. Como se pode observar, cada conjunto de variáveis input é avalia- 
do em termos de um conjunto de regras-bases vagas, que permitirão derivar uma medida global das variáveis inputs intermédias que são: efeito-preço determinado pela estrutura competitiva da indústria e efeito-preço determinado pelas elasticidades da oferta e da procura. Depois, utilizando um novo conjunto de regras vagas, poderemos inferir o efeito da flutuação do escudo no preço dos produtos homogéneos vendidos no mercado interno, uma das variáveis output da componente. $\mathrm{O}$ efeito no preço dos produtos diferenciados vendidos no mercados interno, a outra variável output da componente, é obtido directamente a partir do efeito-preço determinado pela estrutura competitiva da indústria. Multiplicando o efeito-preço obtido pela variação nas taxas de câmbio reais, obteremos a variação no preço dos produtos. Estas avaliações das variações nos preços serão transferidas posteriormente e usadas por outras componentes do modelo.

\section{Figura 2: Variação no Preço dos Produtos Vendidos no Mercado Interno}

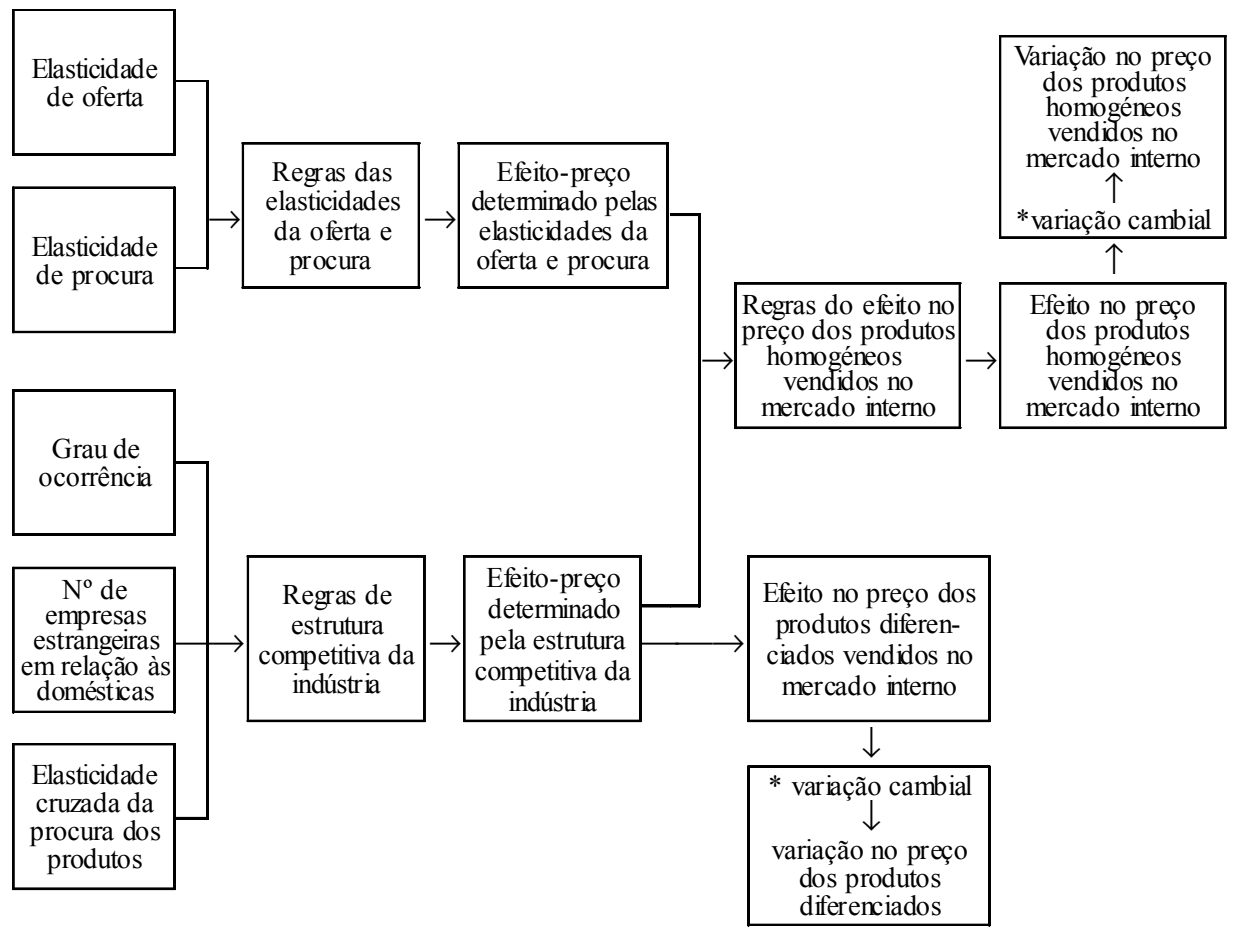

\section{Identificaçăo das Variáveis}

Após o desenvolvimento das componentes torna-se necessário uma identificação mais específica das variáveis. Cada variável pode ser identificada por um conjun- 
to de características qualitativas e a função característica é definida como o conjunto de todos os valores input possíveis e os seus graus de associação ou de pertença com um grupo qualitativo particular.

Assim, para cada variável vaga é necessário definir um universo de discurso e o seu método de representação, bem como a descrição da função característica de pertença. $\mathrm{O}$ universo de discurso tem a ver com uma escala-base e refere-se ao tipo e ao intervalo de valores numéricos usados por uma variável; portanto as variáveis independentes das funções características de pertença representam uma escala numérica.

Muitas variáveis que nos permitem inferir o impacto da variação das taxas de câmbio nos preços e nas quantidades são normalmente manuseadas através dos seus valores linguísticos porque apesar de serem quantificáveis são de difícil quantificação. Como veremos a seguir, as variáveis das primeiras componentes foram definidas com a ajuda de três valores linguísticos: pequeno, médio e grande, utilizando vários universos de discurso de acordo com o significado particular da variável em causa. Nas componentes que determinam os efeitos da flutuação do escudo nos lucros operacionais e na posição competitiva adoptamos, no intuito de sermos mais precisos, cinco valores linguísticos: muito pequeno, pequeno, médio, grande e muito grande. Quanto maior for o número de níveis linguísticos utilizados mais precisa se torna a avaliação do risco de câmbio económico, mas maior é também o número potencial de regras e de avaliações, o que complica o modelo.

A título de exemplo faremos aqui a identificação das variáveis relativas à componente que determina o efeito da flutuação do escudo no preço dos produtos vendidos para o mercado interno:

- Grau de concorrência do mercado (pequeno, médio, grande): para avaliarmos o nível competitivo da estrutura de mercado utilizaremos como escala-base o intervalo de variação da ratio de concentração ${ }^{(2)}$ :

$$
\mathrm{C}_{4}=\underset{\mathrm{i}=1}{\sum_{\mathrm{i}}}
$$

sendo $\mathrm{s}_{\mathrm{i}}$ a quota de mercado de cada uma das quatro maiores empresas do sector.

A escala-base varia de 0 a 1: o grau de concorrência será considerado grande se a ratio de concentração se situar entre 0 e 0,3 ; médio se a ratio de concentração varia de 0,2 a 0,5 ; pequeno se esta ratio for superior a 0,4 . 


\section{Figura 3: Função Característica de Pertence para a Variável Grau de Concorrência do Mercado}

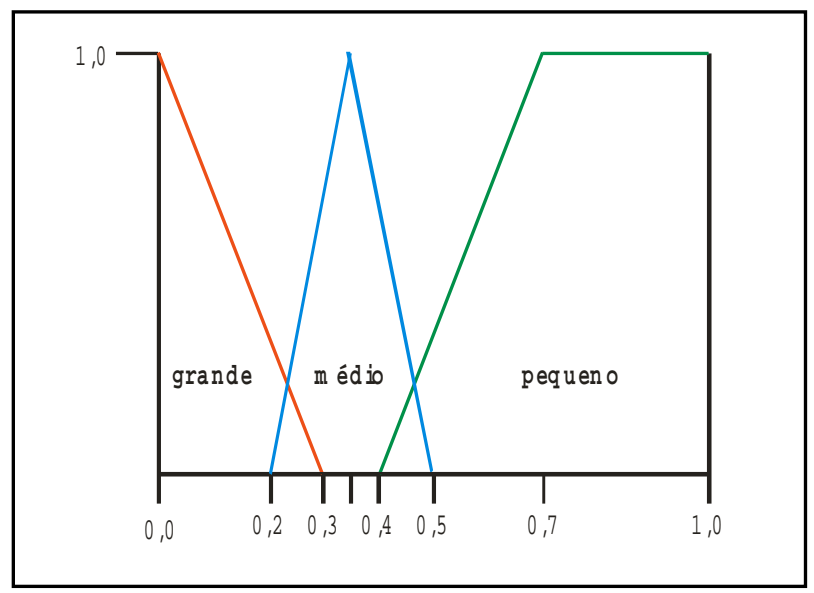

. Número de empresas estrangeiras em relação às domésticas (pequeno, médio, grande): para determinarmos o domínio português dos mercados consideraremos a ratio número de empresas estrangeiras no total das empresas, ou por se tornar mais fácil na prática, a quota de importações no total das vendas no mercado, numa escala que representa a percentagem e, portanto, que varia de 0 a 100 ou de 0 a 1 .

- Elasticidade da procura, elasticidade da oferta, elasticidade cruzada da procura e elasticidade substituição de bens nacionais por bens importados (pequena, média e grande): as funções características de pertença das variáveis respeitantes às elasticidades (quer de importações de produtos ou factores de produção, quer de exportações de produtos) variam de 0 a 3 , sendo considerada pequena se inferior a 1 , média se varia de 0,5 a 1,5 , com máxima possibilidade no valor 1 e grande se maior que 1.

- Efeito no preço (pequeno, médio, grande): o efeito da flutuação do escudo no preço dos produtos ou factores de produção avalia-se em relação a essa flutuação cambial. O modelo procura saber se a variação no preço é idêntica ou muito inferior à variação cambial verificada, ou seja, pretende-se saber qual é a percentagem de variação no preço em relação à variação verificada na taxa de câmbio real. Sendo assim, decidimos que a sua função característica será igual à da variável número de empresas estrangeiras em relação às domésticas, isto é, varia de 0 a 100 , representando a escala-base a percentagem de variação no preço em relação à variação verificada na taxa de câmbio.

Depois de completo o processo de identificação das variáveis torna-se necessário proceder ao desenvolvimento de regras-bases vagas. 


\section{Desenvolvimento de Regras-Bases Vagas}

Como já vimos atrás em esquema, os sistemas de inferência vagos armazenam associações vagas entre as variáveis, em termos de regras do senso comum. Ao contrário dos estimadores estatísticos, este tipo de sistema estima os valores dos outputs sem uma fórmula matemática que dê uma descrição explícita e muitas vezes simplificada de como os outputs dependem dos inputs.

$\mathrm{Na}$ definição das regras-bases muitas vezes utilizaremos premissas-múltiplas. O nível de activação de uma regra que inclui uma intersecção, evidenciada pela conjunção e, é o produto do grau de verdade ou de cumprimento das variáveis incluídas na regra base.

Dado que para cada combinação linguística das variáveis é necessário definir uma regra, isso pode levar a que seja necessário desenvolver um grande número de regras. O número de níveis linguísticos para cada variável influencia o número de regras; por isso consideramos, para as variáveis inputs das primeiras componentes, apenas três níveis (pequeno, médio e grande); mas, se considerássemos cinco (muito pequeno, pequeno, médio, grande e muito grande), então o número de regras potenciais aumentaria muito; contudo o aumento nos níveis linguísticos permitiria uma determinação dos efeitos mais precisa.

As regras-bases serão estabelecidas sempre que possível a partir das opiniões de especialistas recolhidas na literatura relevante; contudo, uma vez que a formulação de todo o conjunto das regras de inferência não está totalmente prevista na literatura e não existe nenhum modelo prévio, tentaremos partir de algumas regras-bases e em seguida extrapolá-las em termos de regras do senso comum de forma a cobrir todas as combinações possíveis das variáveis.

Na definição das regras vagas daremos muitas vezes especial importância ao caso de uma apreciação real da nossa moeda, por ser a variação cambial susceptível de provocar perdas nos resultados e na posição competitiva das empresas do sector têxtil, já que esta apreciação provoca diminuição quer nos preços de venda para os mercados internos, quer nos preços em escudos das exportações.

A apreciação real do escudo baixa os custos das empresas estrangeiras em escudos e, como conseqüência, o equilíbrio do mercado é perturbado em cada parte da indústria e, por isso, deverão ocorrer ajustamentos nos preços e nas quantidades.

A seguir daremos relevo especial à derivação de algumas regras relativas ao efeito da apreciação real do escudo no preço dos produtos vendidos para o mercado interno. 


\section{Efeitos-preço derivados da estrutura competitiva da indústria}

Uma apreciação real do escudo implica sempre uma descida nos preços dos produtos importados, o que leva a um maior ou menor declínio nos preços dos produtos vendidos para o mercado interno. "Vimos agora uma característica comum de vários modelos: todos eles prevêem que a apreciação deverá levar a um declínio no preço das importações" (Dornbush, 1987, p. 102).

Consideraremos que a diminuição nos preços dos produtos pode ser:

- grande: se quase proporcional à apreciação cambial;

média: se menos que proporcional à apreciação cambial;

- pequena: se reduzida ou praticamente nula.

No sentido de derivar os efeitos sobre os preços provocados por uma dada flutuação cambial, Dornbush (1987) começa por utilizar o modelo de Cournot. Este modelo assume substituição perfeita entre produtos alternativos, dando especial ênfase à extensão do oligopólio. Uma vez que a elasticidade do preço de equilíbrio relativamente à taxa de câmbio depende do número relativo de empresas estrangeiras e da ratio do custo marginal em relação ao preço, Dornbush (1987) conclui que a descida no preço em escudos é tanto maior quanto mais concorrencial for a indústria e maior for o número de empresas estrangeiras. Ou seja:

\section{Caso concorrência perfeita $($ preço $=$ custo marginal) e pequeno país:}

Se a elasticidade cruzada da procura é grande e o número de empresas estrangeiras relativamente às domésticas na indústria é grande e o grau de concorrência é grande, então o efeito no preço em escudos é grande.

\section{Caso concorrência perfeita e país grande:}

Quando existe concorrência perfeita, o preço em moeda nacional será pouco afectado com as alterações nas taxas de câmbio, se o mercado for fundamentalmente constituído por produtores e consumidores nacionais. Assim:

Se a elasticidade cruzada da procura é grande e o número de empresas estrangeiras relativamente às domésticas na indústria é pequeno e o grau de concorrência é grande, então o efeito no preço em escudos é pequeno.

Estas duas inferências podem ser encontradas em Flood e Lessard (1986, p. 30), Dornbush (1987, p. 97) e Von Ungern-Sternberg e Von Weizacker (1990, p. 390). 
No caso do oligopólio, ambos os termos da expressão da elasticidade do preço de equilíbrio em relação à taxa de câmbio são fracções, o que significa que a descida no preço em escudos virá como se discrima a seguir.

\section{Caso oligopólio e pequeno país:}

Se a elasticidade cruzada da procura é grande e o número relativo de empresas estrangeiras na indústria é grande e o grau de concorrência é pequeno, então o efeito no preço em escudos é médio.

Von Ungern-Sternberg e Von Weizacker (1990, p. 387) concluem de forma idêntica e dizem: "a variação do preço [...] é uma função crescente dos concorrentes estrangeiros. [...] Quanto maior é a fracção de produtores dos E.U.A., mais pequena é a queda no preço em dólares".

E Dornbush (1987, p. 97):

"o outro caso extremo em que as taxas de câmbio não têm influencia nos preços domésticos surge quando há poucas empresas na indústria, muitas das quais são domésticas. Neste caso, as empresas estrangeiras absorvem a apreciação do dólar mais sob a forma de lucros extranormais do que em aumento das vendas".

\section{Assim, no caso oligopólio e país grande:}

Se a elasticidade cruzada da procura é grande e o número relativo de empresas estrangeiras na indústria é pequeno e o grau de concorrência é pequeno, então o efeito no preço em escudos é pequeno.

Uma vez que o "declínio do preço em escudos é tanto maior quanto mais concorrencial for a indústria (i.e., quanto mais pequena for a diferença entre o preço e o custo marginal) e maior for a quota de importações no total das vendas" (Dornbush, 1987, p. 97), então estaremos em condições de derivar as outras regras que, contudo, não serão explicitadas para evitarmos que o texto se torne demasiado longo.

Se existir diferenciação de produtos, então estaremos perante concorrência monopolística e substituição imperfeita entre os produtos alternativos. Neste caso, uma apreciação cambial levará sempre a uma descida no preço relativo dos bens importados que depende do grau de concorrência e da fracção de empresas que têm os custos fixados em divisas e, então, experimentam uma redução dos seus custos quando o escudo se aprecia em termos reais. 
"Se os produtos são diferenciados acontece sempre que o preço relativo das marcas importadas declina em resposta a uma apreciação. A extensão do declínio depende do grau de concorrência e do número relativo de empresas domésticas e estrangeiras" (Dornbush, 1987, p. 102).

Para analisar os efeitos da flutuação cambial utilizamos o modelo de DixitStiglitz Alargado ${ }^{(3)}$, concluindo que os preços das marcas importadas descem numa proporção inferior ao declínio dos custos em mão-de-obra das empresas estrangeiras e que as empresas domésticas reduzem os seus preços, embora menos que a descida que se verifica nas marcas importadas.

Assim, sabendo que o efeito da flutuação cambial no preço da indústria e no preço relativo depende do número de empresas que têm os salários fixados em divisas e que têm uma redução dos seus custos quando o escudo se deprecia, isto é, do número de empresas estrangeiras, deduzimos as regras a considerar no caso dos produtos diferenciados.

\section{Efeitos-preço derivados das elasticidades da oferta e da procura}

No caso da empresa estar num mercado com características de concorrência perfeita, a variação do preço dos produtos vendidos para o mercado interno provocada por uma flutuação cambial, pode também ser justificada no âmbito do jogo das elasticidades da oferta e da procura. A procura e oferta terão elasticidades consideradas como grandes, se as curvas são muito elásticas ou perfeitamente elásticas; pequenas se as curvas são muito inelásticas ou perfeitamente inelásticas; e médias no caso intermédio (nem muito elásticas, nem muito inelásticas).

Flood e Lessard (1986) mostram, através de alguns exemplos, o impacto das elasticidades da oferta de exportações e da procura das exportações na exposição ao risco de câmbio económico da empresa (efeitos tanto no preço como na quantidade).

Consideremos, então, a oferta e procura de importações das Figuras 4 e 5 . Quando ocorre uma apreciação do escudo, as importações em escudos tornam-se mais baratas, o que faz com que os consumidores aumentem a procura para cada preço em divisa, ou seja, a curva da procura desloca-se para cima. Consequentemente há uma pressão de subida no preço em divisas. 


\section{Figura 4: Caso Geral de uma Apreciação do Escudo: Perspectiva em Divisas}

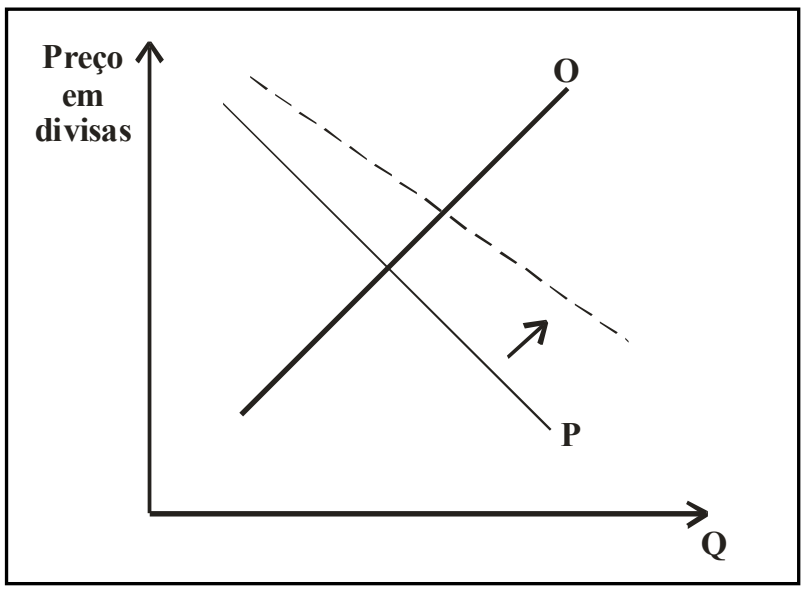

Por outro lado, os produtores estrangeiros oferecem agora mais para cada preço em escudos, ou seja, a curva da oferta desloca-se para baixo. Em consequência, verifica-se uma pressão para descida no preço em escudos.

Figura 5: Caso Geral de uma Apreciação do Escudo: Perspectiva em Escudos

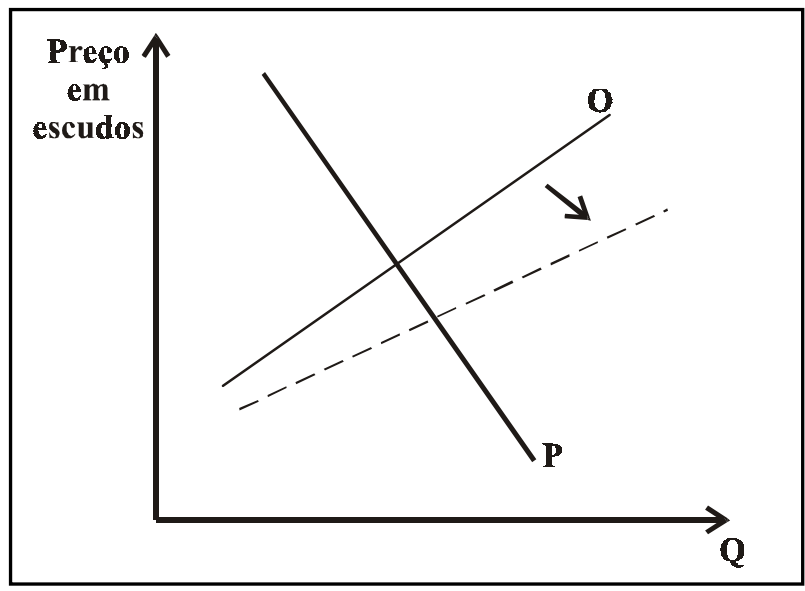

Da conjugação destas duas forças, podemos concluir que o preço das importações diminui, mas menos que a apreciação cambial (só diminuiria na proporção da apreciação se o preço em divisas não se alterasse com a apreciação cambial, nos casos em que a curva da oferta é perfeitamente elástica ou a curva da procura é perfeitamente inelástica). Assim, podemos inferir a seguinte regra:

Se a elasticidade da oferta é média e a elasticidade da procura é média, então o efeito no preço em escudos é médio. 
Consideremos agora o caso em que a procura de bens importados é perfeitamente inelástica. Então, como revela a Figura 6, qualquer variação cambial é repercutida directamente nos consumidores portugueses, o que significa que o preço em escudos vai descer na proporção da apreciação cambial.

\section{Figura 6: Apreciação do Escudo, Caso da Procura Perfeitamente Inelástica}

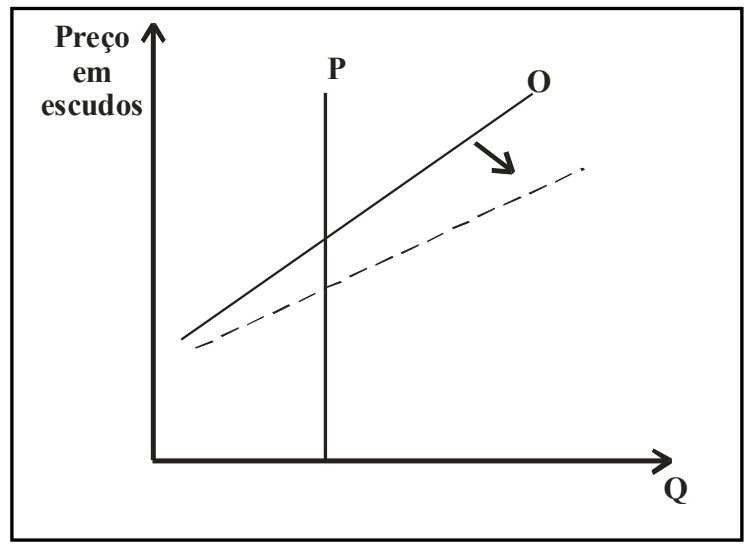

Assim, no caso da procura ser muito ou perfeitamente inelástica e a oferta ter uma inclinação normal:

Se a elasticidade da oferta é média e a elasticidade da procura é pequena, então o efeito no preço em escudos é grande.

E assim sucessivamente...

Cada um destes conjuntos de variáveis ajuda-nos a entender e a prever o efeito de uma variação cambial no preço dos produtos vendidos para o mercado interno. Algumas vezes, poderá acontecer que o efeito no preço previsto por cada conjunto de variáveis possa não ser exactamente o mesmo. Para se chegar a uma conclusão final, pode ser necessário conjugar cada uma das conclusões obtidas em cada conjunto de variáveis através de outro conjunto de regras-bases vagas. No momento em que se estabelecem estas regras é possível dar mais ponderação a algum conjunto de variáveis, considerando que o efeito-preço previsto por esse conjunto domina relativamente ao outro. Assim, no estabelecimento destas regras consideramos que o efeito-preço previsto para os produtos homogéneos pelo conjunto de variáveis relacionadas com a estrutura competitiva é mais importante que o efeito-preço determinado pelas elasticidades. No caso dos produtos diferenciados, o efeitopreço é obtido apenas a partir das regras sobre a estrutura competitiva da indústria.

Como resultado deste processo de inferência surge uma região vaga, que será concretizada através do método do centróide. Obtido o centróide definitivo do 
efeito-preço, multiplicamo-lo pela variação na taxa de câmbio real, verificada ou prevista, obtendo-se a variação no preço. No caso de se ter verificado uma diminuição na taxa de câmbio real (uma apreciação), então obteremos a descida no preço determinada pelo modelo (se estamos a fazer uma análise ex-post), ou a descida que se prevê para o preço (no caso de estarmos a fazer uma previsão).

Após a definição de todas as regras-bases é necessário seleccionar um método de inferência, ou seja, um método que permita correlacionar e agregar toda a evidência proporcionada por cada regra disparada. $O$ método de inferência determina a forma como o valor de uma premissa, ou do seu nível de activação, é aplicado à conclusão.

\section{Selecção das Técnicas de Correlação e Agregação}

As técnicas de correlação e agregação têm um papel muito importante no desenho e processamento de um modelo. No processo de informatização do modelo foi adoptado o método de implicação correlação produto e inferência aditiva porque pensamos que proporciona o melhor mecanismo através do qual as relações entre as variáveis linguísticas podem ser tanto expressas como avaliadas.

\section{Selecção do Método de Concretização}

Como resultado do processo de inferência surge uma região vaga, que poderá ser concretizada para um só valor através de diferentes métodos de concretização. Em muitas circunstâncias torna-se necessário trabalhar com números reais e não com conjuntos vagos e, portanto, na modelação de um sistema vago torna-se importante decidir como converter uma região vaga num número representativo.

No método do centróide, a soma de cada valor do domínio vezes o seu grau de cumprimento é dividido pela soma de todos os graus de cumprimento, o que faz com que não haja a influencia de uma só regra e que o valor esperado do output se mova de uma forma suave ao longo da região vaga. Neste caso, pequenas mudanças nos dados provocam variações contínuas no output. Estes motivos, aliados ao facto de este método ser o que melhor interacção tem (Cox, 1995) com o método de implicação escolhido no ponto anterior, fazem com que seja escolhido e utilizado no modelo.

\section{A Informatização do Modelo}

A folha de cálculo Quattro Pro permite a informatização do modelo (ainda que numa forma não totalmente satisfatória). De facto, foi possível fazer a represen- 
tação numérica e gráfica das variáveis, levar a cabo todo o processo de inferência relativo a preços e quantidades utilizando conjuntos vagos; mas, quando se tornou necessário fazer a soma e multiplicação vagas, dado que a folha de cálculo é ordinária, tivemos de apurar os efeitos nos lucros operacionais a partir dos valores dos centróides dos preços e quantidades e utilizando operações com números reais. Ou seja, determinadas as variações nos preços e quantidades provocadas pela flutuação cambial, tornou-se necessário agregar em termos reais os valores dos centróides dos outputs, com vista a chegar ao efeito nos lucros operacionais.

A possibilidade da simulação, permitida pela informatização do modelo, levounos a acreditar que o trabalho de tratar informaticamente o modelo seria compensatório, apesar de em algumas componentes termos de abandonar os números vagos.

\section{Estudo de Caso: Avaliação da Exposição Económica da Unidade Estratégica de Negódo Fios de uma Grande Empresa Textil Portuguesa}

Através deste modelo, a contabilidade de gestão estratégica consegue avaliar o risco de câmbio económico, calculando de forma aproximada o efeito previsível das flutuações cambiais não só nos lucros operacionais, mas também na posição competitiva da unidade de negócios. Mas, além de cumprir este grande objectivo, julgamos poder dizer que a grande utilidade deste modelo resulta:

- por um lado, de evidenciar que o risco cambial económico surge de múltiplas interacções complexas e mal definidas;

. por outro lado, qualquer tentativa de aplicação a uma empresa permitirá melhorar o entendimento dessas interacções, ou seja, permitirá um melhor conhecimento de como as variações nas taxas de câmbio afectam os preços e quantidades dos seus produtos e factores de produção, ou seja, os seus lucros operacionais e a sua posição competitiva. Esta análise pode ser levada a cabo para o conjunto de moedas que integram a exposição ao risco de câmbio económico ou para cada moeda individualmente.

Uma vez que a aplicação empírica visou não só testar o modelo mas também corrigi-lo, utilizamos um período passado de forte apreciação real do escudo (1988 a 1992 ${ }^{(4)}$ ), com vista a termos a possibilidade de confrontar os efeitos nos preços e nas quantidades obtidos pelo modelo com a realidade da unidade Fios da Alfatex S.A. ${ }^{(5)}$.

Além de se poder concluir que o nível de risco de câmbio económico atingido no período foi muito grande, e que se traduziu em reduções muito importantes nos lucros operacionais e na posição competitiva, o modelo permite evidenciar as 
moedas às quais o negócio está economicamente exposto. Apesar das dificuldades sentidas na obtenção de alguns dados fiáveis, nomeadamente os valores relativos às elasticidades, o estudo levado a cabo mostra que a apreciação do escudo se torna ameaçadora devido às grandes descidas nos preços dos produtos (principalmente dos homogéneos, que são os mais importantes na empresa estudada), nas quantidades vendidas e da posição competitiva, sendo os efeitos benéficos no nível dos factores de produção muito reduzidos. Permite também retirar informações estratégicas que possibilitam, por exemplo, orientar a gestão cambial táctica e operacional do risco de câmbio: definir os limites das taxas de câmbio que levam a abandonar uma moeda ou um mercado de venda de um produto por se verificarem reduções nos lucros operacionais e na posição competitiva, definir as moedas em que deve haver uma estratégia de cobertura financeira sistemática ou esporádica etc.

Se a procura dos produtos têxteis é altamente sensível ao preço e se as alterações nas taxas de câmbio reais provocam alterações nos preços relativos, podendo alterar substancialmente a competitividade internacional, então podemos concluir que as empresas têxteis, e em particular a Alfatex S.A., deverão prestar muita atenção à exposição ao risco de câmbio económico. Identificá-la, saber medi-la e estar informado sobre as oportunidades e as ameaças que a evolução das taxas de câmbio representam é cada vez mais importante num meio de crescente competitividade.

Apesar da criação de União Monetária Europeia e do euro pressupor a eliminação do risco cambial entre as moedas dos países participantes, a verdade é que em termos económicos essa eliminação só será efectiva se não houver variações nos custos de trabalho unitários ponderados pelos ganhos de produtividade em cada país, importando, portanto, que a empresa se mantenha atenta a estes efeitos na posição competitiva. De qualquer maneira, a introdução do euro permitirá simplificar o modelo, permitindo que posteriormente se façam as seguintes melhorias:

- ampliar o modelo, incluindo outras variáveis, de acordo com bibliografia de macroeconomia e economia industrial adequada;

- aumentar os níveis linguísticos: quantos mais conjuntos vagos temos, mais regras temos de derivar e melhor descreveremos o comportamento do sistema.

\section{CONCLUSÕES}

O respeito pelo princípio contabilístico da continuidade da empresa exige uma preocupação pela preservação e extensão da rendibilidade das empresas ao longo 
dos tempos. Ora, isso requer uma gestão do risco de câmbio não só orientada para a exposição de tradução e transacção (ou seja, para o curto prazo), como também requer considerar os efeitos que as flutuações cambiais terão a médio e longo prazo na empresa. Se a rendibilidade é a determinante mais importante no valor de mercado de uma empresa, então interessa construir informação que nos permita conhecer os efeitos de concorrência provocados pela flutuação cambial.

Até aqui a exposição da empresa ao risco de câmbio económico não tem sido gerida por três razões:

. Porque a exposição a este tipo de risco não é publicada e normalmente os efeitos económicos das taxas de câmbio não são da responsabilidade de ninguém. Este problema organizacional das empresas (falta de informação estratégica) deve ser corrigido através da contabilidade de gestão estratégica porque não reconhecer um problema não o resolve.

. Porque se pensa que a exposição a este tipo de risco não pode ser coberta; contudo, por não ser possível uma cobertura total, isso não significa que não pode ser gerida. Por outro lado, este argumento não deve ser dado como desculpa para ignorá-la porque a gestão cambial só pode ser bem conduzida e só terá sentido se se conhecerem todos os impactos das flutuações cambiais.

. Porque a exposição a este risco não é quantificável; mas, se é verdade que o risco cambial económico não pode ser medido de uma forma exacta, isto não significa que não possa ser conhecido de forma aproximada, de maneira a mostrar o impacto de variações cambiais no meio competitivo da empresa.

O modelo de inferência vago que elaboramos surge, quer por acreditarmos que a exposição ao risco de câmbio económico é uma grandeza contabilística imprecisa, quer da necessidade de tratar a ambiguidade e a incerteza associadas com o processo de avaliação do risco de câmbio económico. Os modelos anteriores avaliavam este risco utilizando métodos matemáticos, estatísticos e financeiros, pressupondo que o futuro é uma continuação do passado, ou que o futuro pode ser previsto com certeza. Com este modelo estamos a seguir as palavras de Zebda (1991): ele sugeriu que fossem feitas aplicações da lógica vaga aos problemas da contabilidade e auditoria que são caracterizados pela incerteza e ambiguidade.

Melhorias contínuas no modelo prometem maiores avanços no tratamento da ambiguidade associada com o problema do risco de câmbio económico. Pensamos que a aplicação do raciocínio vago no desenho de um modelo de avaliação do risco de câmbio económico permitiu incorporar factores reconhecidamente importantes, mas ignorados noutros modelos devido à sua natureza ambígua e obter, assim, um modelo aderente à realidade e intuitivamente lógico. O modelo pode ser 
facilmente adaptável às outras unidades estratégicas da Alfatex S.A. e a outros sectores de actividade.

\section{NOTAS}

${ }^{1}$ Esta é também a opinião de Lessard e Lighstone (1986), Flood e Lessard (1986), Chow e Lee (1997).

${ }^{2}$ Brandão (1993, p. 31) salienta que "para que o índice de concentração permita obter uma ideia melhor fundamentada sobre o nível competitivo da estrutura de mercado interno, a quota de mercado de cada empresa deveria ser calculada da seguinte forma:

$$
s_{i}=\frac{x_{i}-\exp _{i}}{X-\exp _{s}+i m p_{s}}
$$

sendo $\exp _{\mathrm{i}}$ as exportações da empresa i e $\exp _{\mathrm{s}}$, imp $\mathbf{s}_{\mathrm{s}}$ as exportações e importações do sector respectivamente". X é o output total do sector.

${ }^{3}$ Neste modelo admitem-se interacções estratégicas com outras empresas por efeito de variações conjunturais, ou seja, ao contrário do modelo anterior assume-se que a empresa individualmente é suficientemente grande para afectar o preço da indústria e que as empresas respondem a variações conjunturais no preço da indústria, numa fracção entre zero e um.

${ }^{4}$ A escolha deste período de cinco anos resulta, para a maior parte das moedas, de a mais baixa taxa de câmbio real do escudo ter sido atingida no início ou ao longo de 1987 e ter sido no segundo trimestre de 1992 que a economia portuguesa atingiu o ponto mais baixo de competitividade externa, ou seja, a maior taxa de câmbio real do escudo.

${ }^{5}$ Por questões relacionadas com o sigilo da informação, designaremos a sociedade estudada pela firma fictícia Alfatex S.A.

\section{ReFERÉnCias Bibliográficas}

BRANDÃO, A.

Estratégias e estruturas industriais em economias abertas. Documentos do IESF, n. 5, 1993.

CHOW, E.;

\section{LEE, W.}

The economic exposure of multinational firms. The Journal of Financial Research, p. 191-210, Summer 1997.
COX, E.

Fuzzy logic for business and industry. Charles River: Rockland, 1995.

DORNBUSCH, R.

Exchange rates and prices. The American Economic Review, p. 93-106, March 1987. 
FLOOD, E.;

LESSARD, D.

On the measurement of operating exposure to exchange rates : a conceptual approach. Financial Management, p. 25-36, Spring 1986.

LESSARD, D.;

LIGHSTONE, J.

Volatile exchange rates can put operations at risk. Harvard Business Review, p. 107-114, July/Aug. 1986.

\section{PITT-WATSON, D.}

Briefing. Euromoney, May 1990.

RANGONE, A.

Linking organizational effectiveness, key success factors and performance measures : an analytical framework. Management Accounting Research, p. 207-219, June 1997.
SIMMONDS, K.

Strategic management accounting. Management Accounting, p. 26-29, 1981.

VON UNGERN-STERNBERG, T; VON WEIZACKER, C. C.

Strategic foreign exchange management. Journal of Industrial Economics, v. 38, p. 381-395, June 1990.

ZADETH, L. A.

Fuzzy sets. Information and Control, v. 8, p. 338-353, 1965.

ZEBDA, A.

The problem of ambiguity and vagueness in accounting. Behavioral Research in Accounting, v. 3, p. 17-45, 1991. 